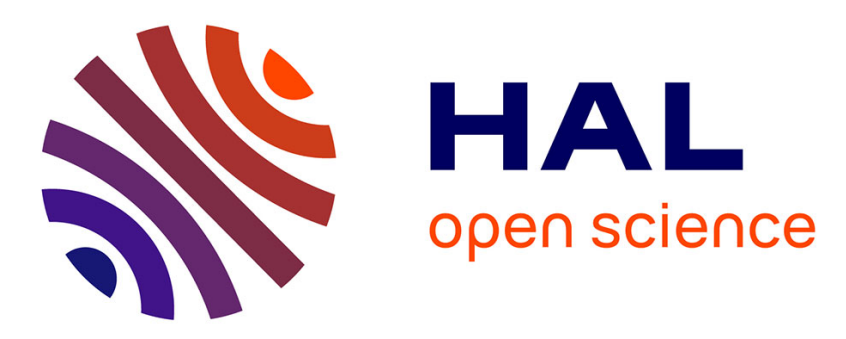

\title{
Three-reaction model for the anaerobic digestion of microalgae
}

Francis Mairet, Olivier Bernard, Elliot Cameron, Monique Ras, Laurent Lardon, Jean-Philippe Steyer, Benoît Chachuat

\section{To cite this version:}

Francis Mairet, Olivier Bernard, Elliot Cameron, Monique Ras, Laurent Lardon, et al.. Three-reaction model for the anaerobic digestion of microalgae. Biotechnology and Bioengineering, 2012, 109 (2), pp.415-425. 10.1002/bit.23350 . hal-00848426

\section{HAL Id: hal-00848426 \\ https:/ /hal.inria.fr/hal-00848426}

Submitted on 14 Apr 2021

HAL is a multi-disciplinary open access archive for the deposit and dissemination of scientific research documents, whether they are published or not. The documents may come from teaching and research institutions in France or abroad, or from public or private research centers.
L'archive ouverte pluridisciplinaire HAL, est destinée au dépôt et à la diffusion de documents scientifiques de niveau recherche, publiés ou non, émanant des établissements d'enseignement et de recherche français ou étrangers, des laboratoires publics ou privés. 


\title{
Three-Reaction Model for the Anaerobic Digestion of Microalgae
}

\author{
Francis Mairet ${ }^{1,2, *}$ Olivier Bernard ${ }^{1}$, Elliot Cameron ${ }^{3}$, Monique Ras $^{4}$, \\ Laurent Lardon ${ }^{4,1}$, Jean-Philippe Steyer ${ }^{4,1}$, Benoît Chachuat ${ }^{5,3}$ \\ ${ }^{1}$ BIOCORE-INRIA, BP93, 06902 Sophia-Antipolis Cedex, France \\ 2 Departamento de Matemática, Universidad Técnica Federico Santa María, \\ Avda España 1680, Valparaíso, Chile \\ ${ }^{3}$ Department of Chemical Engineering, McMaster University, Canada \\ ${ }^{4}$ INRA, UR050, Laboratoire de Biotechnologie de l'Environnement, \\ Avenue des Etangs, Narbonne F-11100, France \\ ${ }^{5}$ Centre for Process Systems Engineering, Department of Chemical Engineering, \\ Imperial College London, UK
}

September 27, 2011

Keywords: Anaerobic digestion, microalgae, dynamic model, Chlorella vulgaris, hydrolysis, Contois kinetics, ammonia inhibition.

${ }^{*}$ Corresponding author, tel : +56 3226547 85, fax : +56 3226545 63, e-mail: francis.mairet@usm.cl 


\section{Abstract}

Coupling an anaerobic digester to a microalgal culture has received increasing attention as an alternative process for combined bioenergy production and depollution. In this paper, a dynamic model for anaerobic digestion of microalgae is developed with the aim of improving the management of such a coupled system. This model describes the dynamics of inorganic nitrogen and volatile fatty acids since both can lead to inhibition and therefore process instability. Three reactions are considered: two hydrolysis-acidogenesis steps in parallel for sugars/lipids and for proteins, followed by a methanogenesis step. The proposed model accurately reproduces experimental data for anaerobic digestion of the freshwater microalgae Chlorella vulgaris with an organic loading rate of $1 \mathrm{gCOD} \cdot \mathrm{L}^{-1} \cdot \mathrm{d}^{-1}$. In particular, the three-reaction pathway allows to adequately represent the observed decoupling between biogas production and nitrogen release. The reduced complexity of this model makes it suitable for developing advanced, model-based control and monitoring strategies. 


\section{Introduction}

Microalgae are currently considered one of the most promising feedstock for biofuels (Rittmann, 2008; Wijffels and Barbosa, 2010). But on the path to making large-scale microalgae culture sustainable, one needs to consider the management of large quantities of residual algal biomass along with the supply of large amounts of fertilizers. Not only does anaerobic digestion appear to be in an ideal position for addressing these two challenges, but it also presents encouraging economic and energetic performances (Sialve et al., 2009; Mussgnug et al., 2010; Zamalloa et al., 2011). Coupling microalgae culture and anaerobic digestion is therefore a promising alternative for producing methane from solar energy (Sialve et al., 2009; De Schamphelaire and Verstraete, 2009; Ehimen et al., 2009). However, due to their inherent complexity, the design and operation of such coupled systems presents many challenges. Mathematical models are particularly helpful for their analysis and design as well as for devising robust control strategies. The emphasis in this paper is on the development of a dynamic model for anaerobic digestion of microalgae, as a first step towards developing a full model of the coupled process.

The anaerobic digestion ecosystem is known to be complex, involving hundreds of bacterial species. While many anaerobic digestion models have been developed since the 1970s, including the well-accepted IWA anaerobic digestion model 1 (ADM1)(Batstone et al., 2002), only one study has been devoted specifically to the modeling of the anaerobic digestion of algal biomass to our knowledge (Mairet et al., 2011b). It was shown that a modified version of ADM1 that employs Contois kinetics for the hydrolysis steps is able to adequately describe the anaerobic digestion of microalgae. But with more than 30 state variables, this model is hardly amenable to mathematical analysis (Bernard and Queinnec, 2008).

Our goal is to develop a reduced model based on experimental data obtained from anaerobic digestion of the freshwater microalgae Chlorella vulgaris over a period of 140 days. We aim to accurately represent the key variables of the process, yet with the lowest possible level of complexity. In particular, we pay special attention to the low biodegradability of common microalgae along with their large nitrogen content which, when converted into ammonia, can inhibit the bacterial activity (Chen et al., 2008).

A two-reaction model, referred to as AM2 subsequently, was developed by Bernard et al. (2001) for anaerobic digestion of highly concentrated wastewater, whereby a population of 
acidogenic bacteria first degrade the organic substrate to produce $\mathrm{CO}_{2}$ and volatile fatty acids (VFAs) and a second population of methanogenic bacteria then consume the VFAs and produce $\mathrm{CO}_{2}$ and methane. This model, which features a good trade-off between accuracy and simplicity, has been widely used for analysis, monitoring and control (Steyer et al., 2006; Hess and Bernard, 2009; Rincon et al., 2009). However, extensive numerical simulation has revealed that AM2 cannot accurately describe the anaerobic digestion of microalgae, especially regarding the fate of nitrogenous compounds. This clearly calls for further developments.

The following procedure is used in this paper to develop a reduced dynamic model. In section 2, we describe the experimental set-up and the methodology used to determine the minimum number of reactions needed to match the variability in the available experimental data set. Then, a reaction scheme is proposed in section 3, based on a simplification of ADM1. In section 4, the resulting model — called MAD (Microalgae Anaerobic Digestion model) herein is calibrated from the available experimental data and the fit quality is compared to that of the modified ADM1. Important features of the MAD model are also discussed in this section.

\section{Materials and Methods}

\subsection{Experimental Methodology}

Experimental Setup Experiments were carried out using the freshwater microalgae Chlorella vulgaris, strain CCAP 211/11B (grown under non-limiting conditions) in a $1 \mathrm{~L}$ continuousstirred-tank anaerobic digester, with $0.1 \mathrm{~L}$ headspace, maintained at $35{ }^{\circ} \mathrm{C}$, and without $\mathrm{pH}$ control.

Feed Stream Characterization A detailed characterization of the feed stream can be found in Ras et al. (2011) and Mairet et al. (2011b). Such feed was introduced as slugs, with an average organic load of $1 \mathrm{~g}$ COD.L $\mathrm{L}^{-1} \cdot \mathrm{d}^{-1}$, while equal volumes of reactor medium were removed to maintain a constant liquid volume. This feed policy was chosen in order for the process to operate under a wide range of conditions, both close to steady state for three different dilution rates and in transient mode by applying large substrate pulses. The dilution rate profile (daily average) along with the substrate additions are shown in Fig. 1. The average concentrations of other relevant inlet components are reported in Tab. I. 
Measurement Techniques The following quantities were measured on a daily basis: total COD (by colorimetric method); ion concentrations (by ion chromatography); biogas volume (by water displacement); biogas composition (by gas chromatography); and $\mathrm{pH}$. Random samples were also selected on a less frequent basis for VFA determination. See Ras et al. (2011) for details on the applied protocols.

\subsection{Determining Model Complexity}

The first step in the modeling methodology applied in section 3 consists in identifying the least number of reactions required to explain the variability in the experimental data set. This analysis can be performed based on principal component analysis (PCA), following the approach described by Bernard and G.Bastin (2005) and Bernard et al. (2006), which is summarized hereafter.

A general mass-balance model of the following form is considered for the system:

$$
\dot{\boldsymbol{\xi}}(t)=\mathrm{K} \mathbf{r}(\cdot)+D(t)\left(\boldsymbol{\xi}^{\mathrm{in}}(t)-\boldsymbol{\xi}(t)\right)-\mathbf{q}(\cdot),
$$

where $\boldsymbol{\xi}, \boldsymbol{\xi}^{\text {in }} \in \mathbb{R}^{n_{\xi}}$ are the state variables in the reactor liquid phase and in the feed stream, respectively; $D$, the dilution rate; $\mathrm{K} \in \mathbb{R}^{n_{\xi} \times n_{r}}$, the stoichiometric matrix; $\mathbf{r} \in \mathbb{R}^{n_{r}}$, the reaction rate vector; and $\mathbf{q} \in \mathbb{R}^{n_{\xi}}$, the gaseous rate vector.

The number of state variables that can be directly measured is quite limited in most biotechnological processes, and the available measurements often correspond to combinations of the state variables, such as total COD. Sometimes, measurements can also be related to the reaction rates, for example for gaseous outflows of low soluble species such as methane. The analysis throughout this subsection is thus conducted for an output vector of the form:

$$
\mathbf{y}=\left(\begin{array}{c}
\mathbf{y}^{\prime} \\
\mathbf{y}^{\prime \prime}
\end{array}\right)=\left(\begin{array}{c}
C^{\prime} \boldsymbol{\xi} \\
C^{\prime \prime} \mathbf{r}(\cdot)
\end{array}\right)
$$

where $n_{y}=n_{y}^{\prime}+n_{y}^{\prime \prime}$ is the total number of measurements, such that $n_{y} \geq n_{r}$. The matrices $\mathrm{C}^{\prime} \in \mathcal{R}^{n_{y}^{\prime} \times n_{\xi}}$ and $\mathrm{C}^{\prime \prime} \in \mathcal{R}^{n_{y}^{\prime \prime} \times n_{r}}$ represent the combinations for the state variables and the reaction rates. 
For any time instants $t_{i}<t_{j}$, let $\mathbf{u}(\cdot, \cdot), \mathbf{v}(\cdot, \cdot)$ and $\mathbf{w}(\cdot, \cdot)$ be defined as:

$$
\begin{aligned}
& \mathbf{u}\left(t_{i}, t_{j}\right)=\left(\begin{array}{l}
\mathbf{y}^{\prime}\left(t_{j}\right)-\mathbf{y}^{\prime}\left(t_{i}\right)-\int_{t_{i}}^{t_{j}} D(t)\left[\mathbf{y}^{\prime i n}(t)-\mathbf{y}^{\prime}(t)\right] d t \\
\int_{t_{i}}^{t_{j}} \mathbf{y}^{\prime \prime}(t) d t
\end{array}\right) \\
& \mathbf{v}\left(t_{i}, t_{j}\right)=\int_{t_{i}}^{t_{j}} \mathbf{r}(\cdot) d t, \quad \text { and } \quad \mathbf{w}\left(t_{i}, t_{j}\right)=\int_{t_{i}}^{t_{j}} \mathbf{q}(\cdot) d t
\end{aligned}
$$

Suppose that $N$ records of $\mathbf{u}(\cdot, \cdot), \mathbf{v}(\cdot, \cdot)$ and $\mathbf{w}(\cdot, \cdot)$ with $N>n_{r}$ are available, and define the matrices $\mathbf{U}=\left(\mathbf{u}\left(t_{0}, t_{1}\right), \ldots, \mathbf{u}\left(t_{N-1}, t_{N}\right)\right)$ and $\mathbf{V}, \mathbf{W}$ alike. From (1) and (2), it is not hard to see that the following linear relationship holds:

$$
\mathrm{U}=\underbrace{\left(\begin{array}{c}
\mathrm{C}^{\prime} \mathcal{K} \\
\mathrm{C}^{\prime \prime}
\end{array}\right)}_{=: \Gamma} \mathrm{V}+\left(\begin{array}{c}
\mathrm{C}^{\prime} \\
\mathbf{0}
\end{array}\right) \mathrm{W} .
$$

Under the additional assumptions that the matrix $\Gamma$ is full rank-which requires that the measurements $\mathbf{y}$ are non redundant - and that the measured liquid species $\mathbf{y}^{\prime}$ are not involved in (significant) liquid-gas transfer - which enforces $\mathrm{W} \approx \mathbf{0}$ - the number of reactions required to describe the data can directly be assessed from the PCA of the matrix $U=\Gamma V$. Specifically, each principal axis is representative of a given reaction, and the corresponding principal component represents the relative proportion of the overall variability in the data set that can be accounted for by that reaction. Dividing by the largest eigenvalue makes it easy to determine the cumulative variability for a set of principal components, and thus the minimum number of reactions required to account for a variability in the data greater than a given threshold; e.g., $95 \%$ of the variability.

In making this PCA analysis, care must be taken to normalize and center the data in each row of $\mathrm{U}$ in order to give the same weighting to all the variables:

$$
\widetilde{\mathrm{U}}_{i}=\frac{\mathrm{U}_{i}-\mu\left(\mathrm{U}_{i}\right)}{\sqrt{N} \sigma\left(\mathrm{U}_{i}\right)}, \quad i=1, \ldots, n_{y},
$$

where $\mu\left(\mathrm{U}_{i}\right)$ and $\sigma\left(\mathrm{U}_{i}\right)$ are, respectively, the mean and the standard deviation of $\mathrm{U}_{i}$. 


\section{Microalgae Anaerobic Digestion Model}

\subsection{Model Development}

Minimum Number of Reactions We start by determining the minimum number of reactions need to explain the variability in the available data by applying the PCA methodology outlined in subsection 2.2. The matrix $\mathrm{U}$ is calculated using the available liquid-phase measurements in total COD, inorganic nitrogen and VFA concentrations, along with the methane flow rate measurements that are representative of the methanogenic bacteria activity. The time instants $t_{1}, t_{2}, \ldots, t_{N+1}$ are directly taken as the measurement times, and cubic spline interpolants are used to compute the integral terms. Note that none of the measured liquid-phase species are involved in liquid-gas transfer, and therefore the PCA results can be interpreted in terms of biological reactions; that is, $\mathrm{U}=\Gamma \mathrm{V}$. PCA is applied to the centered and normalized data, and the cumulative variability for the principal components is presented in Fig. 2. These results show that 2 or 3 reactions are a minimum for explaining, respectively, $95 \%$ and $99 \%$ of the variability in the data set.

Biological Reaction Pathway Having settled on the number of reactions required to describe the available data, the next step in our modeling methodology is to determine the reaction scheme. This step was carried out on the basis of a simplification of ADM1. In order to preserve a strong biological interpretation, a three-reaction scheme was selected.

The algal biomass substrate is first divided in two parts, denoted as $S_{1}$ and $S_{2} . S_{1}$ is mainly composed of sugars and lipids and does not contain nitrogen, while $S_{2}$ mainly consists of proteins and thus contains nitrogen. Both substrates degrade to VFAs, denoted as $S_{3}$, through the action of specific bacterial populations denoted by $X_{1}$ and $X_{2}$, respectively. Finally, as in the AM2 model, a methanogenic population $X_{3}$ converts the VFAs into methane. Unlike ADM1, a separation between lipids and sugars is not considered in order to keep a low model complexity. Finally, a fraction of the microalgae is considered to yield inert substrate, denoted as $S_{I}$, in agreement with batch experiment observations (data not shown).

A summary of the three-biological reactions in the MAD model is as follows (see Fig. 3): 
- VFA production from hydrolysis-acetogenesis of sugars-lipids:

$$
\alpha_{1} S_{1}+\alpha_{2} \mathrm{NH}_{4}^{+} \stackrel{\mu_{1}(\cdot) X_{1}}{\longrightarrow} X_{1}+\alpha_{3} S_{3}+\alpha_{4} \mathrm{CO}_{2}
$$

- VFA and ammonia production from hydrolysis-acetogenesis of proteins:

$$
\alpha_{5} S_{2} \stackrel{\mu_{2}(\cdot) X_{2}}{\longrightarrow} X_{2}+\alpha_{6} S_{3}+\alpha_{7} \mathrm{NH}_{4}^{+}+\alpha_{8} \mathrm{CO}_{2}
$$

- Methane production via methanogenesis of the VFAs:

$$
\alpha_{9} S_{3}+\alpha_{10} \mathrm{NH}_{4}^{+} \stackrel{\mu_{3}(\cdot) X_{3}}{\longrightarrow} X_{3}+\alpha_{11} \mathrm{CH}_{4}^{+}+\alpha_{12} \mathrm{CO}_{2} .
$$

In the following, $S_{i}$ and $X_{i}$ are expressed in gCOD.L ${ }^{-1}$, while $\mathrm{NH}_{4}^{+}, \mathrm{CO}_{2}$ and $\mathrm{CH}_{4}$ are in mol.L $\mathrm{L}^{-1}(\mathrm{M})$.

Biological Reaction Kinetics The specific growth rates for the hydrolysis-acidogenesis reactions $\left(R_{1}\right)$ and $\left(R_{2}\right)$ are modeled as Contois functions of the corresponding substrates:

$$
\mu_{i}\left(S_{i}, X_{i}\right)=\bar{\mu}_{i} \frac{S_{i}}{S_{i}+K_{S i} X_{i}}, \text { for } i=1,2
$$

A Haldane function is used to model the methanogenesis specific growth rate in $\left(R_{3}\right)$, and it is multiplied by an ammonia inhibition term:

$$
\mu_{3}\left(S_{3}, \mathrm{NH}_{3}\right)=\bar{\mu}_{3} \frac{S_{3}}{S_{3}+K_{S 3}+S_{3}^{2} / K_{I 3}} \frac{K_{I_{\mathrm{NH}_{3}}}}{K_{I_{\mathrm{NH}_{3}}}+\mathrm{NH}_{3}} .
$$

Charge Balance and $\mathrm{pH}$ In order to determine the $\mathrm{pH}$ in the digester, all the acid-base pairs are supposed to be in equilibrium. Assuming a $\mathrm{pH}$ no higher than 8 , the concentration of carbonate ions $\mathrm{CO}_{3}^{2-}$ can be neglected and the total inorganic carbon concentration, denoted by $C$, reduces to the sum of the dissolved carbon dioxide concentration $\mathrm{CO}_{2}$ and the bicarbonate concentration $\mathrm{HCO}_{3}^{-}$. Considering the dissociation constant $K_{C}=\frac{h\left[\mathrm{HCO}_{3}^{-}\right]}{\left[\mathrm{CO}_{2}\right]}$ for the pair 
$\mathrm{HCO}_{3}^{-} / \mathrm{CO}_{2}$, the bicarbonate concentration reads:

$$
\left[\mathrm{HCO}_{3}^{-}\right]=\frac{K_{C}}{h+K_{C}} C
$$

where $h=\left[\mathrm{H}^{+}\right]$, expressed in $\mathrm{M}$.

Similarly, dissociation of the total inorganic nitrogen between free ammonia and ammonium ions $\left(N=\left[\mathrm{NH}_{3}\right]+\left[\mathrm{NH}_{4}^{+}\right]\right)$and of the VFA between non-ionized HVFA and ionized $\mathrm{VFA}^{-}$ $\left(S_{3}=[\mathrm{HVFA}]+\left[\mathrm{VFA}^{-}\right]\right)$leads to:

$$
\begin{aligned}
& {\left[\mathrm{NH}_{4}^{+}\right]=\frac{h}{K_{N}+h} N} \\
& {\left[\mathrm{VFA}^{-}\right]=\frac{K_{\mathrm{VFA}}}{K_{\mathrm{VFA}}+h} S_{3},}
\end{aligned}
$$

with $K_{N}=\frac{h\left[\mathrm{NH}_{3}\right]}{\left[\mathrm{NH}_{4}^{+}\right]}$and $K_{\mathrm{VFA}}=\frac{h\left[\mathrm{VFA}^{-}\right]}{[\mathrm{HVFA}]}$ the dissociation constants for the pairs $\mathrm{NH}_{3} / \mathrm{NH}_{4}^{+}$ and $\mathrm{VFA}^{-} / \mathrm{HVFA}$. Assuming that the VFAs are mainly composed of acetate, the dissociation constant of acetate can be used for VFA; note that the dissociation constants of the different VFA as propionate and butyrate are very close anyway.

We define the inert charge imbalance $z$ as follows:

$$
z=\sum\left[\mathrm{Cat}_{I}\right]-\sum\left[\mathrm{An}_{I}\right]
$$

where $\mathrm{Cat}_{I}$ and $\mathrm{An}_{I}$ are those cations and anions not affected by the anaerobic digestion $\left(\mathrm{Na}^{+}\right.$, $\mathrm{K}^{+}, \mathrm{Cl}^{-}$, etc.), multiplied by their valence. Then, charge balance leads to the following equation:

$$
z+\left[\mathrm{NH}_{4}^{+}\right]+h=\left[\mathrm{OH}^{-}\right]+\left[\mathrm{HCO}_{3}^{-}\right]+\left[\mathrm{VFA}^{-}\right] / \tilde{M}_{\mathrm{VFA}}
$$

where $\tilde{M}_{\mathrm{VFA}}$ stands for the COD content of VFAs (64 gCOD.mol ${ }^{-1}$ assuming pure acetate), and $\left[\mathrm{OH}^{-}\right]=K_{\mathrm{H}_{2} \mathrm{O}} / h$.

Combining equations (6), (7) and (9) yields:

$$
\frac{K_{\mathrm{H}_{2} \mathrm{O}}}{h}+\frac{K_{C}}{h+K_{C}} C+\frac{K_{\mathrm{VFA}}}{K_{\mathrm{VFA}}+h} \frac{S_{3}}{\tilde{M}_{\mathrm{VFA}}}-z-\frac{h}{K_{N}+h} N-h=0,
$$

which relates the $\mathrm{pH}\left(=-\log _{10} h\right)$ in the digester to the other state variables $z, N, C$ and $S_{3}$. 
Liquid-Gas Transfer The liquid-gas transfer rate of $\mathrm{CO}_{2}$ (in mol. $\left.\mathrm{L}^{-1} \cdot \mathrm{d}^{-1}\right)$ is modeled as follows:

$$
\begin{aligned}
\rho_{\mathrm{CO}_{2}} & =k_{L} a\left(\left[\mathrm{CO}_{2}\right]-K_{H, \mathrm{CO}_{2}} P_{\mathrm{CO}_{2}}\right) \\
& =k_{L} a\left(\frac{h}{K_{C}+h} C-K_{H, \mathrm{CO}_{2}} P_{\mathrm{CO}_{2}}\right),
\end{aligned}
$$

where $P_{\mathrm{CO}_{2}}$ is the partial pressure of $\mathrm{CO}_{2}$ in the headspace, $K_{H, \mathrm{CO}_{2}}$ Henry's constant for $\mathrm{CO}_{2}$ and $k_{L} a$ the liquid-gas transfer coefficient. On the other hand, we consider that all of the produced methane is transfered to the headspace, due to its very low solubility:

$$
\rho_{\mathrm{CH}_{4}}=\alpha_{11} \mu_{3} X_{3}
$$

The biogas flow rate can be computed by assuming an overpressure in the headspace as:

$$
q_{\text {gas }}=\max \left(0 ; k_{p}\left(P_{\mathrm{CH}_{4}}+P_{\mathrm{CO}_{2}}-P_{a t m}\right)\right),
$$

with $k_{p}$ the pipe resistance coefficient (Batstone et al., 2002). Finally, the methane content $\left(\% \mathrm{CH}_{4}\right)$ of the biogas flow can be obtained as:

$$
\%_{\mathrm{CH}_{4}}=\frac{P_{\mathrm{CH}_{4}}}{P_{\mathrm{CH}_{4}}+P_{\mathrm{CO}_{2}}} .
$$

Mass Balance in the Headspace The dynamics of the partial pressures in $\mathrm{CO}_{2}$ and methane are given by:

$$
\begin{aligned}
& \dot{P}_{\mathrm{CO}_{2}}=-P_{\mathrm{CO}_{2}} \frac{q_{\text {gas }}}{V_{\text {gas }}}+\rho_{\mathrm{CO}_{2}} \frac{V_{\text {liq }} R T_{o p}}{V_{\text {gas }}} \\
& \dot{P}_{\mathrm{CH}_{4}}=-P_{\mathrm{CH}_{4}} \frac{q_{\text {gas }}}{V_{\text {gas }}}+\rho_{\mathrm{CH}_{4}} \frac{V_{\text {liq }} R T_{o p}}{V_{\text {gas }}}
\end{aligned}
$$

where $V_{\text {liq }}$ and $V_{\text {gas }}$ are the volumes of the liquid and gas phases, $T_{o p}$ is the operating temperature, and $R$ is the gas law constant.

Mass Balance in the Liquid Phase Considering a perfectly mixed reactor fed with microalgae characterized by their fraction in sugars-lipids $\beta_{1}$, proteins $\beta_{2}$, and inerts $\beta_{I}$, the dynamics 
of the species concentrations in the liquid phase read:

$$
\begin{aligned}
& \dot{S}_{1}=D\left(\beta_{1} S_{i n}-S_{1}\right)-\alpha_{1} \mu_{1} X_{1} \\
& \dot{S}_{2}=D\left(\beta_{2} S_{i n}-S_{2}\right)-\alpha_{5} \mu_{2} X_{2} \\
& \dot{S}_{3}=-D S_{3}+\alpha_{3} \mu_{1} X_{1}+\alpha_{6} \mu_{2} X_{2}-\alpha_{9} \mu_{3} X_{3} \\
& \dot{X}_{1}=\left(\mu_{1}-D\right) X_{1} \\
& \dot{X}_{2}=\left(\mu_{2}-D\right) X_{2} \\
& \dot{X}_{3}=\left(\mu_{3}-D\right) X_{3} \\
& \dot{N}=D\left(N_{i n}-N\right)-\alpha_{2} \mu_{1} X_{1}+\alpha_{7} \mu_{2} X_{2}-\alpha_{10} \mu_{3} X_{3} \\
& \dot{C}=D\left(C_{i n}-C\right)+\alpha_{4} \mu_{1} X_{1}+\alpha_{8} \mu_{2} X_{2}+\alpha_{12} \mu_{3} X_{3}-\rho_{\mathrm{CO}_{2}} \\
& \dot{z}=D\left(z_{i n}-z\right) \\
& \dot{S_{I}}=D\left(\beta_{I} S_{i n}-S_{I}\right)
\end{aligned}
$$

where $D$ is the dilution rate, $S_{i n}, N_{i n}, C_{i n}$ and $z_{i n}$ are, respectively, the concentrations of COD, inorganic nitrogen, inorganic carbon, and inert charge imbalance in the feed.

Numerical Simulation of the MAD Model Overall, the MAD model consists of the mass balance equations in the headspace (15)-(16) and in the liquid phase (18)-(27), together with the charge balance equation (10). The specific growth rates $\mu_{i}$ in these equations are defined by (4) and (5), with $\mathrm{NH}_{3}=\frac{K_{N}}{K_{N}+h} N$. Moreover, the liquid-gas transfer rates $\rho_{\mathrm{CO}_{2}}$ and $\rho_{\mathrm{CH}_{4}}$ are defined in (11) and (12).

The fact that feed was introduced as sludges during the experiment requires special treatment in the numerical simulations. The effect of each addition (at time $t_{i}$ ) on the liquid-phase concentrations (as represented by the vector $\boldsymbol{\xi}$ ) are computed based on mass-balance considerations as follows:

$$
\boldsymbol{\xi}\left(t_{i}^{+}\right)=\boldsymbol{\xi}\left(t_{i}^{-}\right)+\frac{V_{i n}\left(t_{i}\right)}{V_{l i q}}\left(\boldsymbol{\xi}_{i n}\left(t_{i}\right)-\boldsymbol{\xi}\left(t_{i}^{-}\right)\right)
$$

where $V_{\text {in }}$ and $\boldsymbol{\xi}_{\text {in }}$ are the volume and the concentrations of the feed additions. The MAD model is then solved with $D=0$ until the next feed (from $t_{i}^{+}$to $t_{i+1}^{-}$), and so on. 


\subsection{Model Calibration}

Feed Substrate Characterization Using an average biochemical composition of Chlorella vulgaris (Becker, 2007; Pruvost et al., 2011), Mairet et al. (2011b) have determined COD fractions corresponding to proteins (40\%), lipids (22\%), carbohydrates (8\%) and inerts (30\%). From this characterization, the feed composition parameters $\beta_{1}, \beta_{2}$ and $\beta_{I}$ in the MAD model could be easily deduced, as reported in Tab. II.

Stoichiometric Parameters The values of the stoichiometric coefficients $\alpha_{i}$ in Tab. II were deduced from Batstone et al. (2002) and from conservation laws based on the substrate, product and biomass compositions given in Tab. III.

Kinetic Parameters The kinetic parameters were identified with a minimization algorithm (function fminsearch in Matlab ${ }^{\circledR}$ implementing the Nelder-Mead simplex algorithm (Nelder and Mead, 1965)) using the whole experimental data set, composed of the following measurements: COD $\left(=\sum S+\sum X\right)$, gas flow rate, methane content, VFA and inorganic nitrogen. This algorithm was used to find the set of parameters that minimizes an error criterion $J$ summing the relative errors between the model and the measurements as:

$$
J=\sum_{j=1}^{p} \frac{\omega_{j}}{n_{j}} \sum_{i=1}^{n_{j}}\left(\frac{y_{j}^{e}\left(t_{i}\right)-y_{j}^{m}\left(t_{i}\right)}{\bar{y}_{j}^{m}}\right)^{2},
$$

where, for each measured variable $j, y_{j}^{m}\left(t_{i}\right), y_{j}^{e}\left(t_{i}\right)$ and $\bar{y}_{j}^{m}$ are respectively the measurement and the model estimation at time $t_{i}$ and the average value of the measurement, and $\omega_{j}$ is the weight attributed to the variable $j$.

Moreover, in order to assess the quality of the fit for the various measurements, a fitting index was defined as

$$
I_{j}=\frac{1}{n_{j}} \sum_{i=1}^{n_{j}}\left(\frac{y_{j}^{e}\left(t_{i}\right)-y_{j}^{m}\left(t_{i}\right)}{\bar{y}_{j}^{m}}\right)^{2},
$$

for each measured variable $j$. 


\section{Results and Discussions}

Comparisons with Experimental Data The simulation results are plotted in Fig. 4 (red lines), and parameter values are given in Tab. II. The MAD model describes fairly accurately the experimental data, in particular the COD, VFA and inorganic nitrogen concentrations (Fig. 4 A, C, and E). The gas flow rate is well predicted too (Fig. 4 B), along with the methane content (Fig. 4 D) except at the end of the experiment (after day 100) when larger slugs are fed to the reactor. The liquid-gas transfer model is a possible source of error as large feed slugs can create transients during which $\rho_{\mathrm{CO}_{2}} \leq 0$ and $q_{\text {gas }}=0$. Modeling such large disturbances using a constant mass transfer coefficient $k_{L} a$ may not be suitable. Indeed, the specific interfacial area per unit volume of liquid in the reactor, $a$, is largely dependent on the gas production rate (Pauss et al., 1990; Merkel and Krauth, 1999). Nevertheless, this phenomenon should not occur for a continuous feed policy, therefore the model was not modified. Finally, the discrepancy in the $\mathrm{pH}$ (Fig. $4 \mathrm{~F}$ ) can be attributed to a poor characterization of the feed composition, which was not regularly monitored and probably varied during the 140-day experiment.

The good agreement between the model predictions and the experimental data confirms that a three-reaction system is sufficient to explain the majority of the variability in the data set (see subsection 2.2). Since both inorganic nitrogen and VFA accumulations can lead to inhibition and process instability, the good representation of these species is a first hint that the model shall be suitable for on-line control and monitoring purposes.

In the model simulation, almost all the biodegradable part of the microalgae is digested when low dilution rate are applied (first 70 days in the available data set). On the other hand, a high dilution rate can produce a decrease of the protein degrader population $X_{2}$ and therefore an accumulation of protein $S_{2}$ (see Fig. 5 after day 70), while sugars and lipids are almost completely degraded because of a higher maximal growth rate of $X_{1}$. This leads to a nitrogen release (due to protein degradation) not correlated to the methane production, as it was already observed experimentally (Ras et al., 2011) and with the modified ADM1 (Mairet et al., 2011b). Although it is rarely pointed out, this phenomenon can also be observed, for example, in the anaerobic digestion of primary sludge (Miron et al., 2000). Using two parallel steps for acidogenesis, as it is proposed in the MAD model, is therefore necessary to catch the complex dynamics of microalgae anaerobic digestion. This also explains why a two-reaction 
model such as AM2 could not describe these experiments well.

Recall that it was assumed during model development (see subsection 3.1) that the VFAs are mainly composed of acetate, meaning that acetogenesis is included in the two hydrolysisacidogenesis reactions $\left(R_{1}\right)$ and $\left(R_{2}\right)$. This assumption is necessary in calculating the stoichiometric coefficients and writing the ion balance. Numerical simulations under various operating conditions using the modified ADM1 show that acetate represents over $80 \%$ of VFA (in COD) at steady state. However, this assumption may no longer be verified during long transients, thereby leading to an underestimation of the $\mathrm{pH}$.

Comparisons with ADM1 The predictions of the MAD model are compared with those of the modified ADM1 in Fig. 4. It should be noted that the late was calibrated from the same experimental data set in previous work (Mairet et al., 2011b).

While the MAD model complexity is much lower than that of ADM1, the fit quality of these two models, in terms of the fit indices (30), appear to be almost the same (for total COD, inorganic nitrogen and gas flow rate) or even better (for methane content and VFA) see Tab. IV. Note that for both model calibrations, six parameters were identified using a minimization procedure. Regarding the modified ADM1, only the kinetic parameters involved in the three parallel hydrolysis reactions were estimated, which could explain why the MAD model yields better results. Clearly, the fitting performance of ADM1 could be improved by estimating additional kinetic parameters. However, due to the relatively few measured outputs and the high model complexity, trying to estimate too many parameters inevitably results in structural and practical identifiability issues (Dochain and Vanrolleghem, 2001).

Considerations on Experimental Measurement Techniques Assessing the evolution of the various biomass populations would provide a better insight in the process complexity. It would also be of great help for monitoring the process, and maintain optimal working conditions. However, despite some promising recent studies (Rivière et al., 2009; Carballa et al., 2011), analytical techniques are currently lacking to study the anaerobic microbial diversity. Monitoring microbial population dynamics remains a real challenge. Molecular techniques, such as polymerase chain reaction (PCR), denaturing gradient gel electrophoresis (DGGE) and terminal restriction fragment length polymorphism (T-RFLP), have recently emerged but most 
of these tools remain qualitative, or specific to a bacterial community (Lee et al., 2009). New improvements in analytical techniques are required to quantify and to determine the metabolic functions of all the microorganisms involved in the process. Similarly, the measurements of all the intermediate products at industrial scale would require substantial efforts and costs. Model simulations can thus provide useful estimations of population and substrate dynamics and help to detect sub optimal working modes.

Considerations on Species Conservation Based on the substrate, product and biomass compositions given in Tab. III, the stoichiometric coefficients in Tab. II guarantee that COD and nitrogen are conserved in each reaction. This analysis is shown in Tab. V. On the other hand, the carbon balance is not closed because $S_{3}$ is assumed to be only VFA, while it should also include $\mathrm{H}_{2}$. Nevertheless, the dynamics of $\mathrm{H}_{2}$ and VFA are very different due to the liquid-gas transfer of $\mathrm{H}_{2}$ and a very low half saturation constant for the hydrogenotrophic methanogenesis. In order to keep model complexity as low as possible, $\mathrm{H}_{2}$ was not included in the MAD model. It follows that the model overestimates VFA production in reactions $\left(R_{1}\right)$ and $\left(R_{2}\right)$.

Considerations on Biological Kinetics Hydrolysis is known to be the limiting step in microalgae anaerobic digestion (Mairet et al., 2011b). The Contois model, which includes the saturation of both substrate and biomass, is a reliable way of describing hydrolysis (Vavilin et al., 2008), in particular for microalgae (Mairet et al., 2011b). On the other hand, a Haldane function is suitable to model the methanogenesis specific growth rate as it accounts for VFA inhibition (Bernard et al., 2001). Since methanogens are the least tolerant to ammonia among all the populations involved in anaerobic digestion (Chen et al., 2008), an ammonia inhibition function is used only for this population. Nevertheless, as the experiments were carried out at a low loading rate, no significant inhibitory accumulation of ammonia or VFA could be observed. It follows that the inhibition parameters could not be estimated from these data and their values had to be taken from other studies: Batstone et al. (2002) for ammonia $\left(K_{I_{\mathrm{NH}_{3}}}\right)$ and Bernard et al. (2001) for VFA $\left(K_{I 3}\right)$. These inhibition terms were however retained in the kinetic expressions since they are expected to play an important role in the future use of the model (control and monitoring). 
Applications to Other Microalgae Species Although it was developed and calibrated for the anaerobic digestion of Chlorella vulgaris, we expect that the MAD model can also be used with other microalgae species, provided that some of its parameter values are adjusted. First, the biochemical composition typically varies for each microalgal species and also depends on the culture conditions (nutrients, light, temperature, etc..) (Harrison et al., 1990; Mairet et al., 2011a). Therefore, the feed composition parameters $\beta_{1}, \beta_{2}$ and $\beta_{I}$ must be adjusted for other microalgae species and/or culture conditions. On the other hand, assuming that the main composition of protein, lipid and carbohydrate is constant, the stoichiometric coefficients should not vary too much. Finally, the kinetic parameters should be adjusted for different microalgae species as the digestibility kinetics have shown to be species dependent (Mussgnug et al., 2010). In particular, significant changes are expected for marine species in connection to sodium toxicity (Sialve et al., 2009).

\section{Conclusions}

In this paper, we have proposed a three-reaction model for the anaerobic digestion of microalgae, the so-called MAD model. As the methane and inorganic nitrogen productions are not correlated, the distinction between sugar-lipid and protein degradations is necessary to obtain a good representation of the available experimental data. The fit quality with the MAD model is comparable to that of the modified ADM1 (Mairet et al., 2011b), yet its complexity is much lower, which makes it better suited for mathematical analysis and for derivation of control and monitoring algorithms. As part of future work, we expect to validate the model under higher load conditions; that is, leading to larger ammonia and VFA accumulations and inhibitions. This model will then serve as the basis for optimizing the design and operation of anaerobic digesters when coupled to microalgae culture.

\section{Acknowledgements}

This work benefited from the support of the Symbiose research project founded by the French National Research Agency (ANR). Francis Mairet thanks the support of Fondo Basal, Centro de Modelamiento Matematico - U. de Chile. Elliot Cameron is grateful to NSERC and OGS 
for graduate scholarships.

\section{Nomenclature}

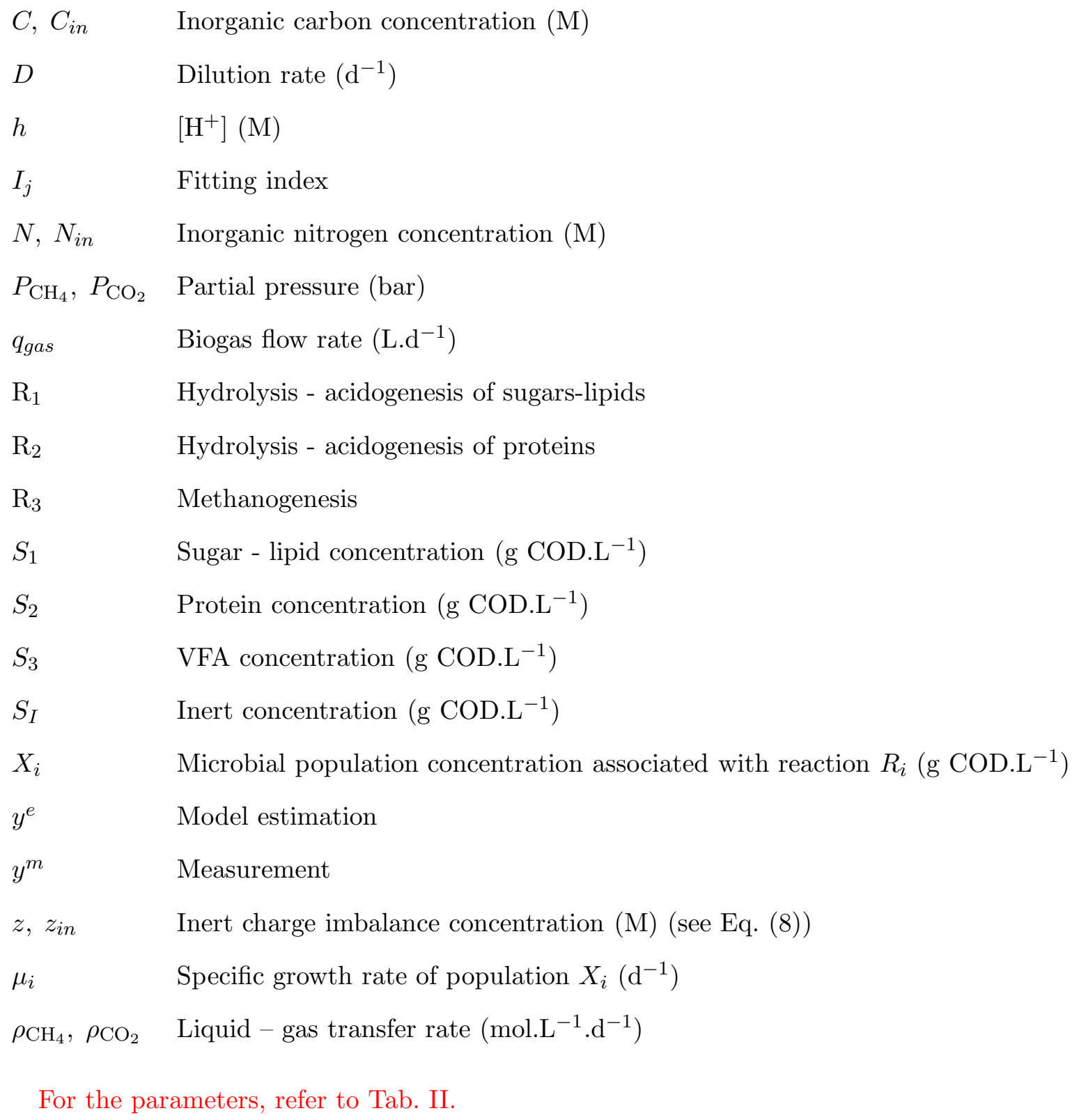

\section{References}

Batstone, D., Keller, J., Angelidaki, R. I., Kalyuzhnyi, S. V., Pavlostathis, S. G., Rozzi, A., Sanders, W. T. M., Siegrist, H., Vavilin, V. A., 2002. Anaerobic Digestion Model No. 1 (ADM1). IWA Publishing, London. 
Becker, E., 2007. Micro-algae as a source of protein. Biotechnology advances 25 (2), 207-210.

Bernard, O., Chachuat, B., Hélias, A., Rodriguez, J., 2006. Can we assess the model complexity for a bioprocess? theory and example of the anaerobic digestion process. Water Science Technology 53, $85-92$.

Bernard, O., G.Bastin, 2005. On the estimation of the pseudo-stoichiometric matrix for mass balance modeling of biotechnological processes. Math. Biosciences 193, $51-77$.

Bernard, O., Hadj-Sadok, Z., Dochain, D., Genovesi, A., Steyer, J., 2001. Dynamical model development and parameter identification for an anaerobic wastewater treatment process. Biotechnology and Bioengineering 75, 424-438.

Bernard, O., Queinnec, I., 2008. Dynamic models of biochemical processes: properties of models. In: D.Dochain (Ed.), Bioprocess Control. Wiley, Hoboken, Ch. 2.

Carballa, M., Smits, M., Etchebehere, C., Boon, N., Verstraete, W., 2011. Correlations between molecular and operational parameters in continuous lab-scale anaerobic reactors. Applied microbiology and biotechnology 89, 303-314.

Chen, Y., Cheng, J., Creamer, K., 2008. Inhibition of anaerobic digestion process: A review. Bioresource technology 99 (10), 4044-4064.

De Schamphelaire, L., Verstraete, W., 2009. Revival of the biological sunlight-to-biogas energy conversion system. Biotechnology and bioengineering 103 (2), 296-304.

Dochain, D., Vanrolleghem, P. A., 2001. Dynamical Modelling and Estimation in Wastewater Treatment Processes. IWA Publishing, London.

Ehimen, E., Connaughton, S., Sun, Z., Carrington, G., 2009. Energy recovery from lipid extracted, transesterified and glycerol codigested microalgae biomass. GCB Bioenergy 1 (6), $371-381$.

Harrison, P., Thompson, P., Calderwood, G., 1990. Effects of nutrient and light limitation on the biochemical composition of phytoplankton. Journal of Applied Phycology 2 (1), 45-56.

Hess, J., Bernard, O., 2009. Advanced dynamical risk analysis for monitoring anaerobic digestion process. Biotechnology Progress 25, $643-653$. 
Lee, C., Kim, J., Hwang, K., O'Flaherty, V., Hwang, S., 2009. Quantitative analysis of methanogenic community dynamics in three anaerobic batch digesters treating different wastewaters. Water Research 43 (1), 157-165.

Mairet, F., Bernard, O., Masci, P., Lacour, T., Sciandra, A., 2011a. Modelling neutral lipid production by the microalga Isochrysis aff. galbana under nitrogen limitation. Bioresource Technology 102, 142-149.

Mairet, F., Bernard, O., Ras, M., Lardon, L., Steyer, J.-P., 2011b. Modeling anaerobic digestion of microalgae using ADM1. Bioresource Technology 102, 6823-6829.

Merkel, W., Krauth, K., 1999. Mass transfer of carbon dioxide in anaerobic reactors under dynamic substrate loading conditions. Water Research 33 (9), 2011-2020.

Miron, Y., Zeeman, G., Van Lier, J., Lettinga, G., 2000. The role of sludge retention time in the hydrolysis and acidification of lipids, carbohydrates and proteins during digestion of primary sludge in cstr systems. Water Research 34 (5), 1705-1713.

Mussgnug, J., Klassen, V., Schluter, A., Kruse, O., 2010. Microalgae as substrates for fermentative biogas production in a combined biorefinery concept. Journal of Biotechnology 150 (1), $51-56$.

Nelder, J., Mead, R., 1965. A simplex method for function minimization. The computer journal 7 (4), 308-313.

Pauss, A., Andre, G., Perrier, M., Guiot, S., 1990. Liquid-to-gas mass transfer in anaerobic processes: inevitable transfer limitations of methane and hydrogen in the biomethanation process. Applied and environmental microbiology 56 (6), 1636.

Pruvost, J., Van Vooren, G., Le Gouic, B., Couzinet-Mossion, A., Legrand, J., 2011. Systematic investigation of biomass and lipid productivity by microalgae in photobioreactors for biodiesel application. Bioresource Technology 102, 150-158.

Ras, M., Lardon, L., Sialve, B., Bernet, N., Steyer, J.-P., 2011. Experimental study on a coupled process of production and anaerobic digestion of Chlorella vulgaris. Bioresource Technology $102,200-206$. 
Rincon, A., Angulo, F., Olivar, G., 2009. Control of an anaerobic digester through normal form of fold bifurcation. J. of Process Control 19 (8), 1355-1367.

Rittmann, B., 2008. Opportunities for renewable bioenergy using microorganisms. Biotechnology and bioengineering 100 (2), 203-212.

Rivière, D., Desvignes, V., Pelletier, E., Chaussonnerie, S., Guermazi, S., Weissenbach, J., Li, T., Camacho, P., Sghir, A., 2009. Towards the definition of a core of microorganisms involved in anaerobic digestion of sludge. The ISME journal 3 (6), 700-714.

Sialve, B., Bernet, N., Bernard, O., 2009. Anaerobic digestion of microalgae as a necessary step to make microalgal biodiesel sustainable. Biotechnol. Advances 27, 409-416.

Steyer, J., Bernard, O., Batstone, D., Angelidaki, I., 2006. Lessons learnt from 15 years of ICA in anaerobic digesters. Water Science and Technology 53, 25-33.

Vavilin, V., Fernandez, B., Palatsi, J., Flotats, X., 2008. Hydrolysis kinetics in anaerobic degradation of particulate organic material: An overview. Waste Management 28 (6), 939-951.

Wijffels, R., Barbosa, M., 2010. An Outlook on Microalgal Biofuels. Science 329 (5993), 796-799.

Zamalloa, C., Vulsteke, E., Albrecht, J., Verstraete, W., 2011. The techno-economic potential of renewable energy through the anaerobic digestion of microalgae. Bioresource Technology $102(2), 1149-1158$. 


\section{Tables}

Table I: Feed characterisation

\begin{tabular}{lcl}
\hline Parameter & Value & Meaning \\
\hline$z_{i n}$ & $0.017 \mathrm{M}$ & Inert charge imbalance concentration \\
$\mathrm{pH}_{i n}$ & 9.6 & \\
$C_{i n}$ & $0.019 \mathrm{M}$ & Inorganic carbon concentration \\
$N_{\text {in }}$ & $0.011 \mathrm{M}$ & Inorganic nitrogen concentration \\
\hline
\end{tabular}


Table II: Parameter values in the MAD model

\begin{tabular}{|c|c|c|}
\hline Parame & Value & Meaning (Reaction) Source \\
\hline \multicolumn{3}{|c|}{ Microalgae characterisation } \\
\hline$\overline{\beta_{1}}$ & 0.3 g COD.g COD $^{-1}$ & Sugar-lipid content of microalgae ${ }^{a}$ \\
\hline$\beta_{2}$ & 0.4 g COD.g $\mathrm{COD}^{-1}$ & Protein content of microalgae ${ }^{a}$ \\
\hline$\beta_{I}$ & 0.3 g COD.g COD ${ }^{-1}$ & Inert content of microalgae ${ }^{a}$ \\
\hline \multicolumn{3}{|c|}{ Stoichiometric parameters } \\
\hline$\alpha_{1}$ & 12.5 g COD.g COD ${ }^{-1}$ & yield for sugar-lipid degradation $\left(\mathrm{R}_{1}\right)^{b}$ \\
\hline$\alpha_{2}$ & 0.0062 mol.g $\mathrm{COD}^{-1}$ & yield for $\mathrm{NH}_{4}^{+}$consumption $\left(\mathrm{R}_{1}\right)^{b}$ \\
\hline$\alpha_{3}$ & 11.5 g COD.g COD ${ }^{-1}$ & yield for VFA production $\left(\mathrm{R}_{1}\right)^{b}$ \\
\hline$\alpha_{4}$ & 0.03 mol.g $\mathrm{COD}^{-1}$ & yield for $\mathrm{CO}_{2}$ production $\left(\mathrm{R}_{1}\right)^{b}$ \\
\hline$\alpha_{5}$ & $9.1 \mathrm{~g}$ COD.g $\mathrm{COD}^{-1}$ & yield for protein degradation $\left(\mathrm{R}_{2}\right)^{b}$ \\
\hline$\alpha_{6}$ & 8.1 g COD.g COD ${ }^{-1}$ & yield for VFA production $\left(\mathrm{R}_{2}\right)^{b}$ \\
\hline$\alpha_{7}$ & 0.054 mol.g $\mathrm{COD}^{-1}$ & yield for $\mathrm{NH}_{4}^{+}$production $\left(\mathrm{R}_{2}\right)^{b}$ \\
\hline$\alpha_{8}$ & 0.03 mol.g COD ${ }^{-1}$ & yield for $\mathrm{CO}_{2}$ production $\left(\mathrm{R}_{2}\right)^{b}$ \\
\hline$\alpha_{9}$ & 20 g COD.g COD ${ }^{-1}$ & yield for VFA consumption $\left(\mathrm{R}_{3}\right)^{b}$ \\
\hline$\alpha_{10}$ & 0.0062 mol.g $\mathrm{COD}^{-1}$ & yield for $\mathrm{NH}_{4}^{+}$consumption $\left(\mathrm{R}_{3}\right)^{b}$ \\
\hline$\alpha_{11}$ & 0.30 mol.g $\mathrm{COD}^{-1}$ & yield for methane production $\left(\mathrm{R}_{3}\right)^{b}$ \\
\hline$\alpha_{12}$ & 0.20 mol.g COD ${ }^{-1}$ & yield for $\mathrm{CO}_{2}$ production $\left(\mathrm{R}_{3}\right)^{b}$ \\
\hline \multicolumn{3}{|c|}{ Kinetic parameters } \\
\hline $\bar{\mu}_{1}$ & $0.30 \mathrm{~d}^{-1}$ & Maximum specific growth rate $\left(\mathrm{R}_{1}\right)^{c}$ \\
\hline$K_{S 1}$ & 2.11 g COD.g COD ${ }^{-1}$ & Contois half saturation constant $\left(\mathrm{R}_{1}\right)^{c}$ \\
\hline $\bar{\mu}_{2}$ & $0.053 \mathrm{~d}^{-1}$ & Maximum specific growth rate $\left(\mathrm{R}_{2}\right)^{c}$ \\
\hline$K_{S 2}$ & 0.056 g COD.g COD ${ }^{-1}$ & Contois half saturation constant $\left(\mathrm{R}_{2}\right)^{c}$ \\
\hline $\bar{\mu}_{3}$ & $0.14 \mathrm{~d}^{-1}$ & Maximum specific growth rate $\left(R_{3}\right)^{c}$ \\
\hline$K_{S 3}$ & $0.02 \mathrm{~g} \mathrm{COD} . \mathrm{L}^{-1}$ & Haldane half saturation constant $\left(\mathrm{R}_{3}\right)^{c}$ \\
\hline$K_{I 3}$ & 16.4 g COD.L $\mathrm{L}^{-1}$ & Haldane inhibition constant $\left(\mathrm{R}_{3}\right)^{d}$ \\
\hline$K_{I_{\mathrm{NH}_{3}}}$ & $0.0018 \mathrm{M}$ & Ammonia inhibition constant $\left(\mathrm{R}_{3}\right)^{b}$ \\
\hline \multicolumn{3}{|c|}{ Physico-chemical parameters } \\
\hline$K_{C}$ & $4.9 \mathrm{e}-7 \mathrm{M}$ & Dissociation constant for the couple $\mathrm{HCO}_{3}^{-} / \mathrm{CO}_{2}{ }^{b}$ \\
\hline$K_{N}$ & $1.1 \mathrm{e}-9 \mathrm{M}$ & Dissociation constant for the couple $\mathrm{NH}_{3} / \mathrm{NH}_{4}^{+}$ \\
\hline$K_{\mathrm{VFA}}$ & $1.7 \mathrm{e}-5 \mathrm{M}$ & Dissociation constant for the couple $\mathrm{VFA}^{-} / \mathrm{HVFA}^{b}$ \\
\hline$K_{\mathrm{H}_{2} \mathrm{O}}$ & $2.1 \mathrm{e}-14 \mathrm{M}$ & Dissociation constant for the couple $\mathrm{H}_{2} \mathrm{O} / \mathrm{OH}^{-b}$ \\
\hline$K_{\mathrm{H}, \mathrm{CO}_{2}}$ & $2.7 \mathrm{e}-2 \mathrm{M} \cdot \mathrm{bar}^{-1}$ & Henry's constant for $\mathrm{CH}_{4}{ }^{b}$ \\
\hline$R$ & $8.31 \mathrm{e}-2$ bar. $\mathrm{M}^{-1} \cdot \mathrm{K}^{-1}$ & Gas law constant ${ }^{b}$ \\
\hline$k_{L} a$ & $5 d^{-1}$ & Gas-liquid transfer coefficient \\
\hline$k_{p}$ & 5e4 L.d $\mathrm{d}^{-1} \cdot \mathrm{bar}^{-1}$ & Pipe resistance coefficient ${ }^{b}$ \\
\hline$V_{l i q}$ & $1 \mathrm{~L}$ & Reactor liquid volume \\
\hline$V_{\text {gas }}$ & $0.1 \mathrm{~L}$ & Reactor gas volume \\
\hline$T_{o p}$ & $308.15 \mathrm{~K}$ & Reactor temperature \\
\hline
\end{tabular}


Table III: Substrate, product and biomass compositions: COD, carbon and nitrogen contents

\begin{tabular}{|c|c|c|c|c|}
\hline \multicolumn{2}{|c|}{ Variable Description } & $\begin{array}{l}\text { COD content } \\
(\mathrm{g} \mathrm{COD} / \mathrm{mol})\end{array}$ & $\begin{array}{l}\text { Carbon content } \\
(\mathrm{mmol} \mathrm{C} / \mathrm{g} \mathrm{COD})\end{array}$ & $\begin{array}{l}\text { Nitrogen content } \\
(\mathrm{mmol} \mathrm{N} / \mathrm{g} \mathrm{COD})\end{array}$ \\
\hline$S_{1}$ & Sugar $\left(\mathrm{C}_{6} \mathrm{H}_{12} \mathrm{O}_{6}\right)-\operatorname{lipid}\left(\mathrm{C}_{40} \mathrm{H}_{74} \mathrm{O}_{5}\right)^{*, a}$ & 547 & 24.7 & 0 \\
\hline$S_{2}$ & Protein $\left(\mathrm{C}_{4.43} \mathrm{H}_{7} \mathrm{O}_{1.44} \mathrm{~N}_{1.16}\right)^{a}$ & 175 & 25.3 & 6.63 \\
\hline$S_{I}$ & Inert ${ }^{* *, a}$ & 246 & 25.1 & 3.81 \\
\hline$S_{3}$ & VFA (acetate: $\mathrm{C}_{2} \mathrm{H}_{4} \mathrm{O}_{2}$ ) & 64 & 31.2 & 0 \\
\hline$X_{i}$ & Biomass $^{b}$ & 160 & 31.3 & 6.25 \\
\hline $\mathrm{CH}_{4}$ & Methane & 64 & 15.6 & 0 \\
\hline
\end{tabular}

* : composition (on a COD basis): sugar $27 \%$, lipid $73 \%$.

** : composition (on a COD basis): protein $57 \%$, sugar $12 \%$, lipid $31 \%$.

$a$ : from Mairet et al. (2011b), $b$ : from Batstone et al. (2002). 
Table IV: Comparison of the fit qualities with the MAD and modified ADM1 models; a smaller value means a better fit.

\begin{tabular}{lcc}
\hline Measurement & \multicolumn{2}{c}{ Fitting Index $I_{j}$} \\
\cline { 2 - 3 } & MAD model & Modified ADM1 \\
\hline Total COD & 0.059 & 0.053 \\
Inorganic nitrogen & 0.011 & 0.016 \\
Gas flow rate & 0.36 & 0.41 \\
$\% \mathrm{CH}_{4}$ & 0.0063 & 0.020 \\
VFA & 1.0 & 2.5 \\
Mean & 0.3 & 0.6 \\
\hline
\end{tabular}


Table V: Biological reactions: COD, nitrogen and carbon balances

\begin{tabular}{lccccccccc}
\hline $\mathrm{R}_{1}$ & $\alpha_{1} S_{1}$ & + & $\alpha_{2} \mathrm{NH}_{4}^{+}$ & $\longrightarrow$ & $X_{1}$ & + & $\alpha_{3} S_{3}$ & + & $\alpha_{4} \mathrm{CO}_{2}$ \\
\hline $\mathrm{g}$ COD & 12.5 & + & 0 & $=$ & 1 & + & 11.5 & + & 0 \\
$\mathrm{mmol} \mathrm{N}$ & 0 & + & 6.2 & $=$ & 6.2 & + & 0 & + & 0 \\
$\mathrm{mmol} \mathrm{C}$ & 309 & + & 0 & $\neq$ & 31 & + & 359 & + & 30 \\
\hline $\mathrm{R}_{2}$ & $\alpha_{5} S_{2}$ & $\longrightarrow$ & $X_{2}$ & + & $\alpha_{6} S_{3}$ & + & $\alpha_{7} \mathrm{NH}_{4}^{+}$ & + & $\alpha_{8} \mathrm{CO}_{2}$ \\
\hline $\mathrm{g}$ COD & 9.1 & $=$ & 1 & + & 8.1 & + & 0 & + & 0 \\
$\mathrm{mmol} \mathrm{N}$ & 60.3 & $=$ & 6.2 & + & 0 & + & 54.1 & + & 0 \\
$\mathrm{mmol} \mathrm{C}$ & 230 & $\neq$ & 31 & + & 253 & + & 0 & + & 30 \\
\hline $\mathrm{R}_{3}$ & $\alpha_{9} S_{3}$ & + & $\alpha_{10} \mathrm{NH}_{4}^{+}$ & $\longrightarrow$ & $X_{3}$ & + & $\alpha_{11} \mathrm{CH}_{4}$ & + & $\alpha_{12} \mathrm{CO}_{2}$ \\
\hline $\mathrm{g} \mathrm{COD}$ & 20 & + & 0 & $=$ & 1 & + & 19 & + & 0 \\
$\mathrm{mmol} \mathrm{N}$ & 0 & + & 6.2 & $=$ & 6.2 & + & 0 & + & 0 \\
$\mathrm{mmol} \mathrm{C}$ & 626 & + & 0 & $\neq$ & 31 & + & 300 & + & 200 \\
\hline
\end{tabular}




\section{List of Figures}

1 Feed rate and additions of Chlorella vulgaris during the 140-day experiment. . . 27

2 Total variance explained with respect to the number of reactions for the anaerobic digestion of Chlorella vulgaris. . . . . . . . . . . . . . . . 28

3 Fluxes of COD and nitrogen for the anaerobic digestion of microalgae as described by the MAD model. . . . . . . . . . . . . . . . . . . . . . 29

4 Anaerobic digestion of Chlorella vulgaris: experimental data (black dots); MAD model (solid red lines); modified ADM1 (Mairet et al., 2011b) (blue dashed lines). 30

$5 \quad$ Prediction of substrate and bacteria population dynamics with the MAD model. A substrate and its associated bacteria population are represented with the same

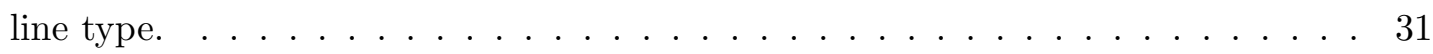




\section{Figures}
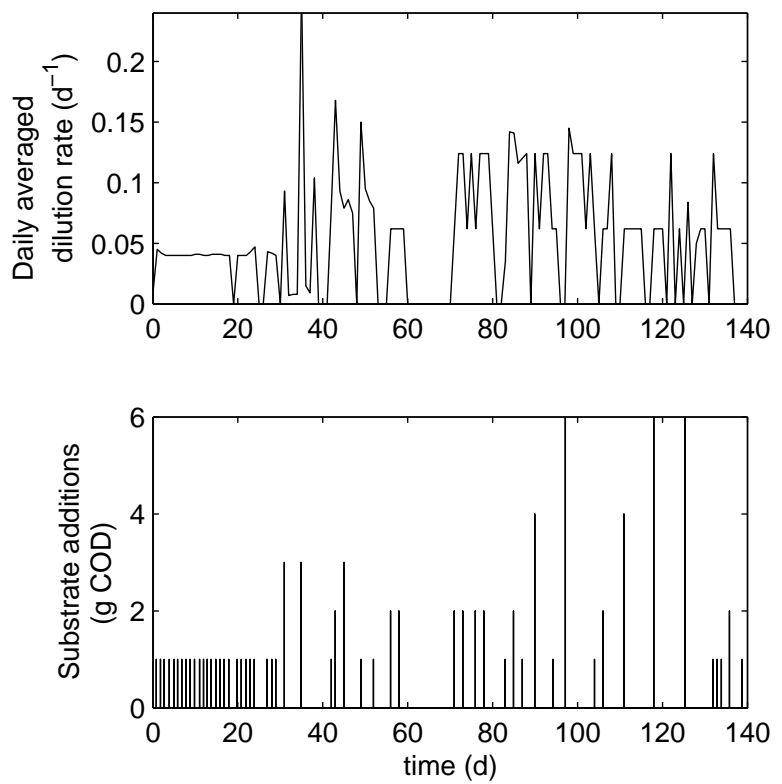

Figure 1: Feed rate and additions of Chlorella vulgaris during the 140-day experiment. 


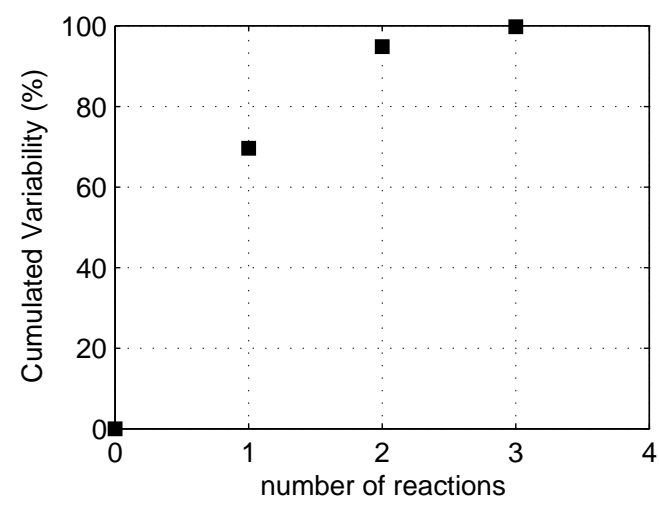

Figure 2: Total variance explained with respect to the number of reactions for the anaerobic digestion of Chlorella vulgaris. 


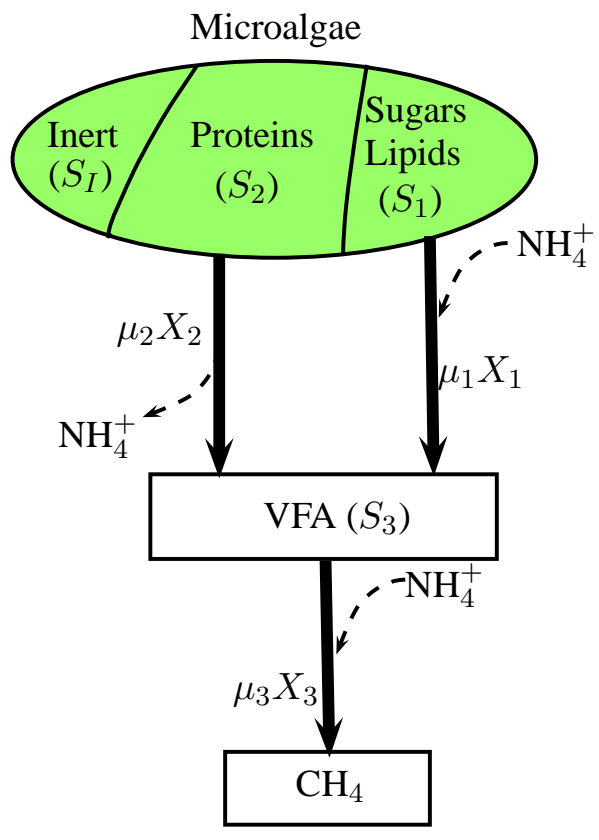

Figure 3: Fluxes of COD and nitrogen for the anaerobic digestion of microalgae as described by the MAD model. 
$\mathrm{A}$

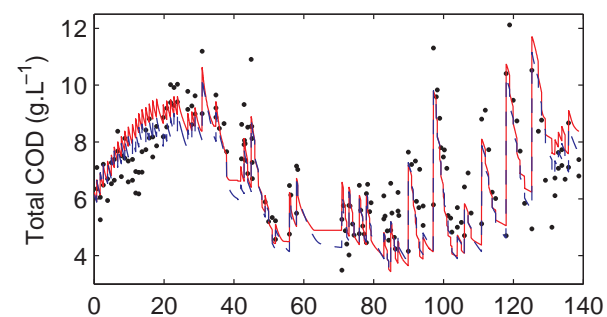

C

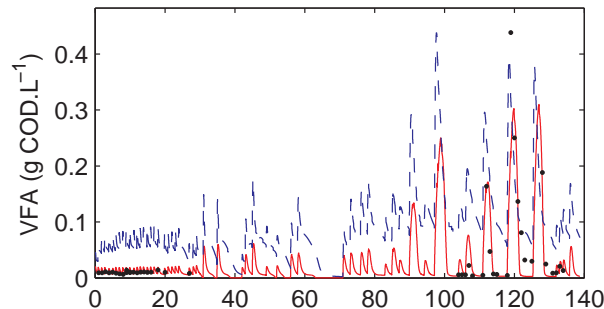

$\mathrm{E}$

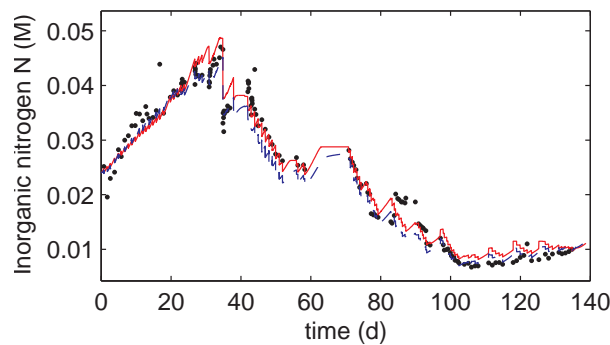

B

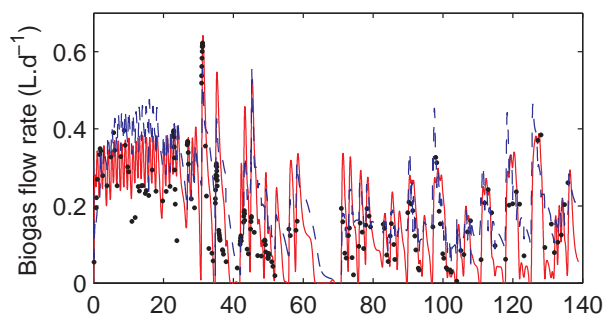

D

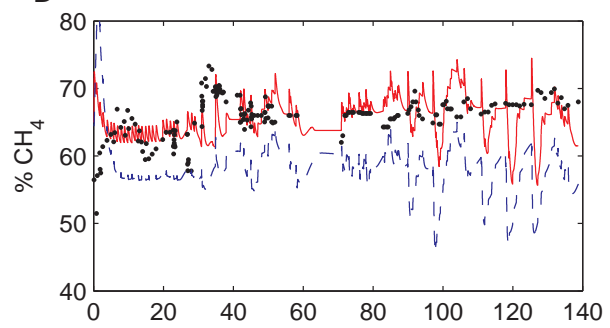

F

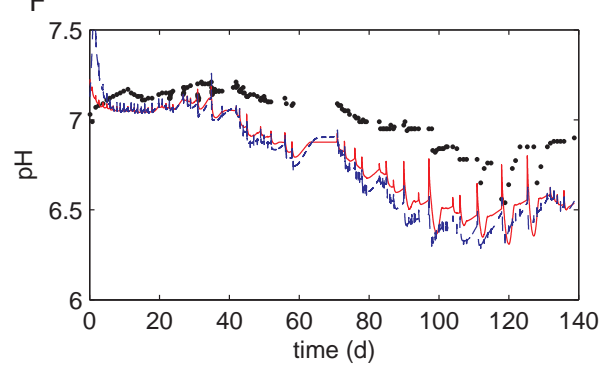

Figure 4: Anaerobic digestion of Chlorella vulgaris: experimental data (black dots); MAD model (solid red lines); modified ADM1 (Mairet et al., 2011b) (blue dashed lines). 

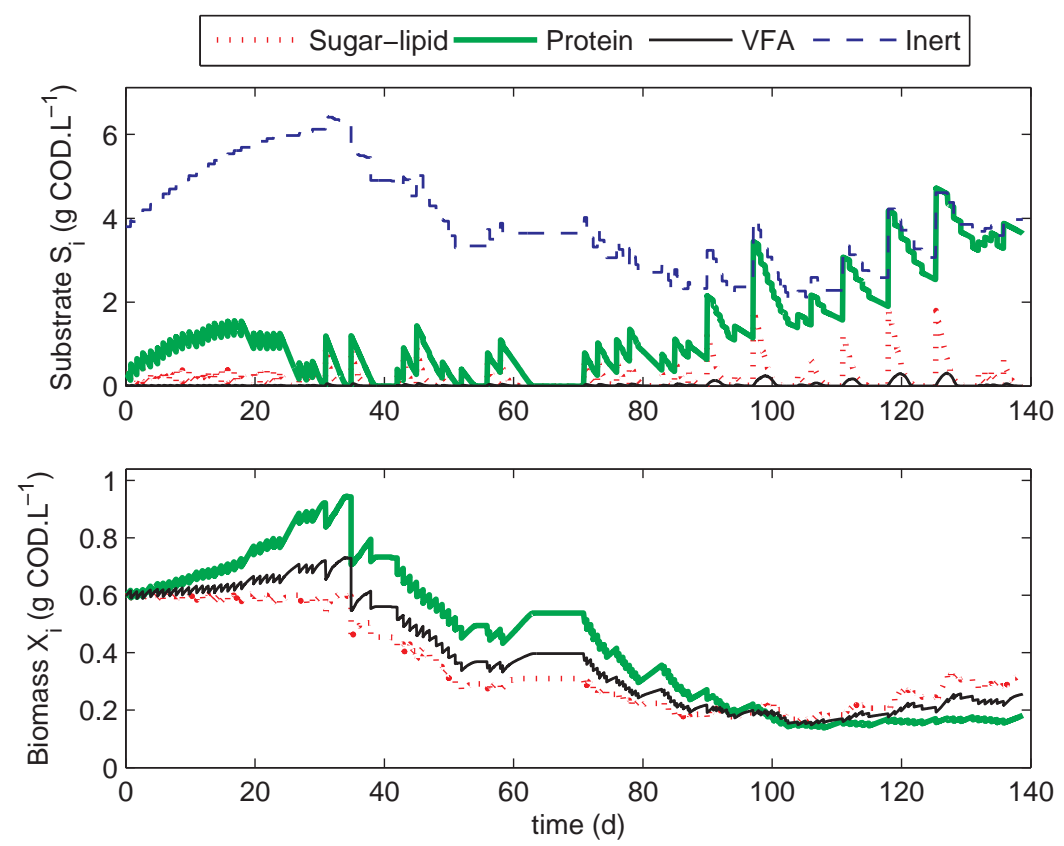

Figure 5: Prediction of substrate and bacteria population dynamics with the MAD model. A substrate and its associated bacteria population are represented with the same line type. 